University of Nebraska - Lincoln

DigitalCommons@University of Nebraska - Lincoln

Faculty Publications, Department of Psychology

Psychology, Department of

April 2004

\title{
Extending the revelation effect to faces: Haven't we met before?
}

Brian H. Bornstein

University of Nebraska-Lincoln, bbornstein2@unl.edu

Jeffrey R. Wilson

Louisiana State University

Follow this and additional works at: https://digitalcommons.unl.edu/psychfacpub

Part of the Psychiatry and Psychology Commons

Bornstein, Brian H. and Wilson, Jeffrey R., "Extending the revelation effect to faces: Haven't we met before?" (2004). Faculty Publications, Department of Psychology. 179.

https://digitalcommons.unl.edu/psychfacpub/179

This Article is brought to you for free and open access by the Psychology, Department of at DigitalCommons@University of Nebraska - Lincoln. It has been accepted for inclusion in Faculty Publications, Department of Psychology by an authorized administrator of DigitalCommons@University of Nebraska - Lincoln. 


\title{
Extending the revelation effect to faces: Haven't we met before?
}

\author{
Brian H. Bornstein \\ University of Nebraska-Lincoln \\ Jeffrey R. Wilson \\ Louisiana State University, Baton Rouge
}

\begin{abstract}
The revelation effect is an episodic memory phenomenon where participants are more likely to report that they recognized an item when it is judged after an interpolated task than when it is not. Although this effect is very robust, nearly all of the extant research has used verbal or readily verbalizable stimuli. The present two experiments examined whether a revelation effect could be produced with non-verbal stimuli such as faces. A revelation effect was found in both experiments, for both targets and lures, using faces as stimuli. The findings are integrated into the prevailing empirical frameworks for the revelation effect and face recognition memory.
\end{abstract}

The revelation effect is an episodic memory phenomenon that has received considerable attention in recent years (see Hicks \& Marsh, 1998, for review). One reason for the interest in this effect is its odd nature. The revelation effect is demonstrated in retrieval tasks - most commonly recognition memory testswhere participants are more likely to report that they recognized previously presented stimuli when they engage in some interpolated task before making their recognition judgments. For example, participants are shown a list of words during the study phase. At test, participants are shown both the study words (i.e., targets) and new words (i.e., lures) and asked to identify the words they recognized from the study list. However, during the recognition phase, half of the words are "revealed" in some fashion (e.g., by solving an anagram of the word to be recognized or completing a word fragment), with the result that participants report recognizing the revealed words (both targets and lures) to a greater degree than words presented normally. Thus, the revelation effect demonstrates that retrieval conditions can be manipulated to influence people's memory. Although most demonstrations of the revelation effect have employed recognition memory tests, it has also been obtained-again using verbal stimuli-when participants are asked to make frequency judgments (Bornstein \& Neely, 2001; Westerman \& Greene, 1996).

The revelation effect appears to be restricted to episodic memory judgments in young adults (Cameron \& Hockley, 2000; Frigo, Reas, \& LeCompte, 1999; Watkins \& Peynircioglu, 1990; Westerman, 2000). Revelation effects are not found in older adults (Prull, Light, Collett, \& Kennison, 1998) or when participants make semantic judgments, such as judging words based on their lexicality or category typicality (Watkins \& Peynircioglu, 1990), but it has otherwise proven to be quite robust. The empirical results of the

Correspondence should be addressed to Brian H. Bornstein, 238 Burnett Hall, Dept. of Psychology, University of Nebraska, Lincoln, NE 68588, USA. Email: Bbornstein2@unl.edu

Jeffrey R. Wilson is now at Microsoft, Redmond, Washington.

This research was conducted as part of the second author's doctoral dissertation at Louisiana State University, under supervision of the first author. Portions of this research were presented at the 2000 meeting of the Psychonomic Society. We are grateful to William Hockley and Bruce Whittlesea for helpful comments on a previous version of the manuscript. 
revelation effect prompted Westerman and Greene (1998) to comment that "Attempts to determine the boundary conditions of the revelation effect have, so far, succeeded mostly in demonstrating its generality" (p. 378). Thus, continuing to define the boundaries or generality of the revelation effect is essential in terms of theory testing.

A variety of interpolated tasks have been used to demonstrate the revelation effect. The most common tasks include having participants solve anagrams of the words before making recognition judgments (e.g., Frigo et al., 1999; Peynircioglu \& Tekcan, 1993), gradually completing degraded words (Luo, 1993) or word fragments (e.g., LeCompte, 1995; Watkins \& Peynircioglu, 1990), and rotating stimuli (e.g., Frigo et al., 1999; Watkins \& Peynircioglu, 1990).

The revelation effect is not limited to words. Some research has also investigated the revelation effect with numbers. For example, participants have been given Roman numerals and asked to convert them to Arabic numerals before making recognition judgments about whether they saw that number on the study list. Also, participants who received numbers at study have had to solve math problems at test and then decide whether their answer was on the study list. Revelation effects were found for both of these tasks (Watkins \& Peynircioglu, 1990). These findings are not surprising, as numbers are similar to words in the respect that they have ready, probably automatic, verbal designations.

Only a single experiment has reported a revelation effect with pictorial stimuli. Luo (1993, Experiment 2) presented pictures of ordinary objects and animals to participants at study, and again on a later recognition test. For half of the participants, the name of the picture was revealed prior to recognition by presenting it letter by letter until the word was completed. For example, a picture of a house would be presented at study; at test, the word H-O-U-S-E would gradually be presented, and then participants would make a recognition judgment regarding the picture of a house. Luo found that participants were more likely to say they recognized the picture if the name of the picture was first revealed to them. Although this experiment demonstrated that a revelation effect could occur for non-verbal study items, two points should be noted. First, it is not clear whether a revelation effect would have occurred if the picture itself had been revealed in some fashion instead of the picture's verbal label; second, the procedure required using pictures that elicited easy and universal verbal encodings, making it ambiguous to what extent the study stimuli were, in fact, encoded non-verbally in the first place.

One area in which the revelation effect has been largely unaddressed is recognition memory for faces. ${ }^{1}$ Based on Luo's (1993) research, it may be inviting to think that a revelation effect would also occur for faces. However, it is not clear whether a revelation effect would occur in face recognition memory. Although some research suggests that facial and pictorial recognition differ from each other in terms of perceptual processing (Farah, Wilson, Drain, \& Tanaka, 1998), there has also been research to suggest that face recognition memory is comparable to picture recognition memory, and that both face and picture recognition memory are different from verbal memory (Church \& Winograd, 1986).

Luo's (1993) finding of a revelation effect with pictures can be explained by assuming that pictures can be represented in a verbal system. In fact, Farah et al. (1998) recently concluded that face recognition and word recognition operate in two separate representational systems, where pictures can be processed within either of the two systems. In contrast, faces are not easily verbalized (Farah et al., 1998). Therefore, Luo may have found a revelation effect when words were used as the interpolated task in picture recognition because the pictures were processed verbally.

If a revelation effect occurs for faces, it demonstrates the robustness of this phenomenon across episodic tasks and stimuli (i.e., words and faces) that are typically considered to be entirely unrelated in terms of cognitive processing (Farah et al., 1998) and recognition memory (Church \& Winograd, 1986). On the other hand, if the revelation effect does not occur for faces, then a specific boundary condition has been identified.

\section{EXPERIMENT 1}

Inverted words have been used to demonstrate a revelation effect with verbal stimuli (e.g., Frigo et al., 1999). An analogous situation for determining whether a revelation effect can be achieved in face recognition memory is to show faces upside down.

\footnotetext{
${ }^{1}$ The only extant article we know of is in a Turkish journal that we were unable to obtain (see Tekcan \& Peynircioglu, 2001).
} 
The present experiment adhered to common revelation effect methodology, with the principal exception that faces were used as the study stimuli. A $2 \times$ 2 (targets vs lures; revealed vs intact) within-subject design was used. During the study phase, participants viewed a set of faces. At test, participants saw a subset of the faces from the study list (targets) mixed in with new faces (lures), and they made judgments on whether they recognized the faces from the study list. For the "intact" condition, participants saw half of the faces (both targets and lures) presented normally and were then prompted with a command asking them if they recognized the face from the study list. For the rest of the faces (the "revealed" condition), participants made an attractiveness judgment about an upside-down face before it was inverted, whereupon they were prompted to make a recognition judgment on the face. Thus, participants made recognition judgments on both targets and lures, and when the faces were presented intact or revealed.

Because face recognition is an episodic memory phenomenon and revelation effects have been obtained in comparable episodic tasks using verbal stimuli, we hypothesized that a revelation effect would occur for faces.

\section{Method}

Participants. The participants were 64 undergraduates from psychology courses who received extra course credit. The pool of participants from which the sample was drawn was predominantly white, female, and in the 18-25-year-old age range. Participants' race and gender were included as covariates in both experiments. As neither covariate accounted for a significant amount of the explained variance, they are not discussed further.

Materials. A large number of black-and-white photos of Caucasian female faces $(N=160)$ were collected from a high-school yearbook. The yearbook was from a time and place that ensured the faces would be unfamiliar to participants. These faces were transferred to slides and then pilot tested to eliminate distinctive faces, by asking participants to rate each face on a 7 -point scale ( $1=$ not distinctive, $7=$ distinctive). Faces that received distinctiveness ratings significantly less than 4 (on the 7-point scale) were considered not to be distinctive. Of the original 160 faces, 140 non-distinct faces were chosen for the present series of experiments, 100 of which were randomly selected to be used in the first experiment.

Design and procedure. A $2 \times 2$ (targets vs lures; revealed vs intact) within-subject design was used. During the study phase, participants were shown 60 faces, presented by slide projector. The first and last 10 faces from the study list were excluded from the test phase to reduce primacy and recency effects. Each face was displayed for 3 seconds.

At test, participants saw 40 faces from the study list (targets) and 40 new faces (lures). Each face was seen for 4 seconds. Participants were asked to make (yesno) judgments on whether they recognized the faces from the study list. For half of the faces (both targets and lures), participants saw the faces presented normally and were then prompted with a command asking them if they recognized the face from the study list. The rest of the faces were presented upside down initially (for 2s), and then the same face was shown normally (2s). Although the degree of effort involved in the interpolated task does not predict the magnitude of the revelation effect (Luo, 1993; Peynircioglu \& Tekcan, 1993), all revelation tasks require participants to perform some sort of judgment or manipulation on the stimulus, so that they give it some minimal level of attention (Hicks \& Marsh, 1998). To ensure attention to the interpolated task, participants were asked to make attractiveness ratings (on a 10-point scale) for the faces when they were presented upside down. Participants were told to wait until they saw the inverted face normally before making a recognition judgment. Thus, participants made recognition judgments on both targets and lures, and when the faces were presented intact or revealed.

The faces were counterbalanced across conditions, so that faces revealed for one set of participants were intact for the other set of participants, and vice versa. The sequence of revealed and intact faces was determined randomly, with the constraint that an equal number of targets and lures and revealed and intact items occurred in the first 40 and the last 40 test trials. Participants were tested in groups of up to 10 people. The experiment lasted approximately 30 minutes, and when participants finished they were debriefed and awarded their extra credit. 


\section{Results and discussion}

The revelation effect has been measured in different ways by previous researchers. Most research on the revelation effect has compared the difference in the number of items called "old" by participants for the intact versus revealed conditions (e.g., Westerman \& Greene, 1998). However, signal detection measures have also been used to examine the nature of the responses given by participants when exposed to intact items compared to revealed items (e.g., Hicks \& Marsh, 1998). For recognition memory, $d$ ' is a measure of how well participants discriminate between targets and lures, and $C$ is a measure of response bias. Signal detection measures such as $d^{\prime}$ and $C$ appear to offer some value in understanding the underlying causes of the revelation effect (Hicks \& Marsh, 1998; Luo, 1993). For the sake of completeness, the data in the present research were analyzed both ways.

Participants were significantly more likely to respond "yes" to targets than to lures, $F(1,63)=141.2$, $p<, 001, M S e=9.21$ (see Table 1). Thus, participants were significantly more likely to say they recognized faces that they had seen before compared to new faces never seen.

A significant revelation effect was also found, $F(1$, $63)=5.32, p<.05, \mathrm{MSe}=6.35$ (see Table 1): Revealed faces were significantly more likely to be called "old" than intact faces. This main effect of revelation condition extends the revelation effect to a new class of stimuli: faces. The revelation effect appears to be a highly robust phenomenon that is not limited to verbal information. The target/lure $\times$ revelation interaction was not significant, $F(1,63)<4.0, p>.05$.

Signal detection analyzes revealed that $d$ ' was not significantly different between intact $(M=.61)$ and revealed items $(M=.56)$; however, $C$ was significant-

TABLE 1

Percentage of faces judged "old" by condition in Experiment 1

\begin{tabular}{llllll}
\hline & \multicolumn{3}{c}{ Revelation condition } & \\
\cline { 2 - 4 } Item & $\begin{array}{c}\text { Revealed } \\
(\%)\end{array}$ & \multicolumn{2}{c}{$\begin{array}{c}\text { Intact } \\
(\%)\end{array}$} & $S D$ & Total \\
\hline Targets & 58 & 16 & 55 & 18 & 56.5 \\
Lures & 37 & 16 & 32 & 15 & 34.5 \\
Total & 47.5 & 43.5 & 45.5 \\
\hline
\end{tabular}

ly greater for intact items $(M=.17)$ than for revealed items $(M=.06), t(63)=2.53, p<.05$. These analyzes indicate that the difference in performance between revealed and intact items does not reflect a difference in discriminability between the two conditions; rather, participants applied a lower criterion for responding "old" to revealed items.

\section{EXPERIMENT 2}

The revelation effect has also been demonstrated by making the revealed stimulus different from the stimulus judged for recognition (Westerman \& Greene, 1996). For example, a positive response bias is found if the word raindrop is revealed and participants are asked if they recognized vineyard. Experiment 2 replicates Experiment 1, while employing this variant of the interpolated task. Using the same manipulation as in Experiment 1 (i.e., stimulus inversion), Experiment 2 revealed new faces that were different from the faces that participants judged at test. Based on the results of Experiment 1, as well as analogous procedures using verbal stimuli (Bornstein \& Neely, 2001; Westerman \& Greene, 1996), we hypothesized a revelation effect for this procedure as well.

\section{Method}

Participants. The participants were 52 undergraduates from psychology courses who received extra course credit.

Materials. The materials were identical to Experiment 1 with the exception that 40 new faces were used in the revelation task. The 40 new faces were selected from the pool of faces that had been normed in the pilot study for Experiment 1.

Design and procedure. The $2 \times 2$ design and procedure were identical to Experiment 1, with the sole exception that the revealed face was different from the face participants were asked to make a recognition judgment about at test. Thus, the revealed faces were completely novel to the participants. On half of the test trials ("revelation" condition), a novel inverted face (from the new set of faces) was displayed prior to asking the participants whether they recognized the (different) test face. As in Experiment 1, participants rated the inverted face for its attractiveness. On 
the remaining test trials, the test faces were presented normally ("intact" condition).

It should be noted that this procedure is not precisely analogous to the raindrop-vineyard procedure used with verbal stimuli (see Bornstein \& Neely, 2001; Westerman \& Greene, 1996). In that situation, participants have typically been required to solve the interpolated anagram before judging the (different) test item for recognition. Thus, they come to know the identity of the interpolated item. Here, participants do not "solve" the interpolated upside-down face before judging the (different) face for recognition. Because upside-down faces are processed relatively poorly, especially unfamiliar ones (Yin, 1969), participants may not "know" an interpolated upside-down face as well as they would an interpolated anagram, in the sense of forming an organized percept of it. Nonetheless, the procedure accomplishes the major goal of requiring participants to engage in an interpolated task involving a stimulus that is different from the test stimulus, yet drawn from the same class of stimuli.

\section{Results and discussion}

Participants were significantly more likely to respond "yes" to targets than to lures, $F(1,51)=267.54$, $p<.001, M S e=4.37$ (see Table 2). Thus, participants were significantly more likely to say they recognized faces that they had seen previously compared to faces never before seen.

A significant revelation effect was also found, $F(1$, $51)=4.98, p<.05, M S e=4.08$ (see Table 2). Revealed faces were significantly more likely to be called "old" than intact faces. Therefore, Experiment 2 replicated the revelation effect found in Experiment 1 , and it also demonstrated that the interpolation of different faces can produce the revelation effect. This

TABLE 2

Percentage of faces judged "old" by condition in Experiment 2

\begin{tabular}{|c|c|c|c|}
\hline \multirow[b]{2}{*}{ Item } & \multicolumn{2}{|c|}{ Revelation condition } & \multirow[b]{2}{*}{ Total } \\
\hline & $\begin{array}{l}\text { Revealed } \\
\text { (\%) } S D\end{array}$ & $\begin{array}{l}\text { Intact } \\
\text { (\%) } S D\end{array}$ & \\
\hline Targets & $54 \quad 15$ & 5216 & 53 \\
\hline Lures & $31 \quad 14$ & $27 \quad 15$ & 29 \\
\hline Total & 42.5 & 39.5 & 41 \\
\hline
\end{tabular}

finding is analogous to the empirical findings of the revelation effect for words (Westerman \& Greene, 1996). The target/lure $\mathrm{x}$ revelation interaction was not significant, $F(1,51)<4.0, p>.05$.

Signal detection analyzes revealed that $d$ 'was not significantly different between intact $(M=.69)$ and revealed items $(M=.60)$; however, $C$ was significantly greater for intact items $(M=.31)$ than for revealed items $(M=.20), t(51)=2.71, p<.01$. These analyzes indicate that the difference in performance between revealed and intact items does not reflect a difference in discriminability between the two conditions, but a lower criterion for responding "old" to revealed items.

\section{GENERAL DISCUSSION}

The present experiments demonstrate that a revelation effect occurs in face recognition memory. This finding is incorporated into the general frameworks of research on the revelation effect and face recognition memory, respectively.

\section{Implications for the revelation effect}

The revelation effect has been found with a variety of stimuli: words, numbers, pictures of concrete objects, and now faces. Nearly all previous demonstrations of the revelation effect have used either verbal or easily (and perhaps automatically) verbalized stimuli, such as numbers and pictures of concrete objects (but see Tekcan \& Peynircioglu, 2001). The present findings demonstrate a revelation effect with genuinely non-verbal stimuli. Of course, faces do not completely lack verbal encodings (e.g., "big nose"), but unfamiliar faces will not have a single verbal designation that characterizes the whole stimulus, in the way that a numeral or picture of a concrete object would (Farah et al., 1998).

As demonstrated in previous research (Hicks \& Marsh, 1998), the revelation effect for faces was larger for lures (i.e., false alarms) than for targets (i.e., hits; see Tables 1 and 2). Hicks and Marsh explain the stronger effect for lures in terms of a "decrement-tofamiliarity" interpretation of the revelation effect. According to their account, revelation produces a liberal shift in participants' response criterion, and "more liberal shifts in the criterion increase false-alarm rates more than hit rates" (Hicks \& Marsh, 1998, p.1118). 
The decrement-to-familiarity account is consistent with the present results. By activating competing alternatives, revealing upside-down faces may increase the signal-to-noise ratio and thereby make test items seem less familiar. According to Hicks and Marsh, this increased task difficulty would result in a more liberal response bias, and consequently more "old" responses to revealed than to intact faces. In support of this account, participants in both experiments adopted a more liberal response criterion for revealed than intact items.

The present findings are also consistent with the other leading explanation of the revelation effect, Westerman and Greene's (1998) Global Matching Model, which suggests that revealing items generates trace activation for the particular class of stimuli being revealed. If the test item and revealed item are from the same class of stimuli, this would produce an enhanced feeling of familiarity for the revealed test items compared to intact test items. The revelation task used here-judging an inverted face for attractiveness - could make the test stimulus seem more familiar than it would in the intact condition, thereby supporting the Global Matching Model. One might expect the increase in familiarity to be greater in Experiment 1 (which revealed the same face as the test item) than in Experiment 2 (which revealed a different face), and indeed, the revelation effect was somewhat greater in Experiment 1 (4\% vs 3\%). However, it is impossible to know whether this small difference across experiments is meaningful, and given the difficulty in recognizing upside-down faces (Yin, 1969), it might not matter whether or not the face judged for recognition was actually the same as the face shown as part of the interpolated task.

Although the present findings do not disambiguate between competing theories of the revelation effect, they nonetheless add to the accumulating literature demonstrating that it is a nearly ubiquitous phenomenon. The revelation effect has already been found with a wide range of interpolated tasks using primarily verbal stimuli. The present experiments demonstrated a revelation effect for faces when the interpolated task consisted of inverting upside-down faces. It should also be noted that the size of the effects obtained here was relatively modest $(2-3 \%$ for targets, $4-5 \%$ for lures), compared to previous research (on average, $6.4 \%$ for targets, $9.9 \%$ for lures; Hicks \& Marsh, 1998). Revelation effects with non-verbal stimuli may ultimately prove to be smaller (albeit still significant) than with verbal stimuli; but the validity of this conjecture awaits further research using non-verbal stimuli. Thus, the only real boundary conditions that exist for the revelation effect are that it appears (1) to be a retrieval phenomenon that is limited to episodic memory tasks based on stimulus familiarity (e.g., Cameron \& Hockley, 2000; Westerman, 2000), and (2) not to occur in elderly participants (Prull et al., 1998).

\section{Implications for face recognition}

It is also important to consider how the present results fit into the literature on face recognition memory. Some research suggests that face recognition memory does not differ from picture recognition memory, while face and picture recognition memory taken together are different from verbal memory (Church \& Winograd, 1986). This dichotomy seems at odds with Luo's (1993) finding of a revelation effect when words were revealed prior to pictorial recognition judgments. However, Luo's (1993) finding of a revelation effect using words as the interpolated task in picture recognition can be explained by assuming that pictures - especially concrete ones of the type used by Luo - can also be represented in a verbal system (Farah et al., 1998). Therefore, Luo's revelation effect may have been produced when words were used as the interpolated task in picture recognition because the pictures were processed verbally. In contrast, Farah et al. (1998) summarize a long list of research studies in support of the claim that faces are not processed verbally. However, the finding of a revelation effect for faces when faces were used in the interpolated task suggests that face recognition memory is not immune to some of the same retrieval phenomena that affect verbal stimuli.

There are practical implications of procedures, such as revelation, that produce a response bias in face recognition memory. In eyewitness identification situations, for example, it is common for people to look through pictures of criminal suspects, in the context of mugshot searches or photographic lineups. If witnesses initially saw a face that was inverted or partially covered, and then the face was shown normally, they might be more likely to say that they recognized the person, compared to just seeing the intact photo. Also, it is important to remember that the revelation effect occurs for lures and is, in fact, slightly stronger 
for them than for targets (Hicks \& Marsh, 1998; see Tables 1 and 2). Considerable anecdotal and empirical research has documented that false positive identifications are a significant problem in eyewitness testimony (Wells et al., 1998). Therefore, it is important to minimize conditions that may contribute to false positive identifications, such as "revealing" the lineup stimuli.

\section{Conclusion}

The revelation effect literature has heretofore relied almost exclusively on verbal, or easily verbalized, stimuli. The present experiments demonstrated that a revelation effect can be produced with faces as stimuli. This extension of the revelation effect to non-verbal stimuli suggests that it appears to hold new surprises, and to raise more questions, as it continues to be studied.

Submitted January 2002; accepted May 2002; published online 30 July 2003

\section{REFERENCES}

Bornstein, B.H., \& Neely, C.B. (2001). The revelation effect in frequency judgment. Memory \& Cognition, 29, 209213.

Cameron, T.E., \& Hockley, W.E. (2000). The revelation effect for item and associative recognition: Familiarity versus recollection. Memory \& Cognition, 28, 176-183.

Church, V., \& Winograd, E. (1986). Face recognition is not unique: Evidence from individual differences. In H. Ellis, M. Jeeves, F. Newcombe, \& A. Young (Eds.), Aspects of face processing (pp. 71-77). Dordrecht: Martinus Nijhoff.

Farah, M.J., Wilson, K.D., Drain, M., \& Tanaka, J.N. (1998). What is "special" about face perception? Psychological Review, 105, 482-498.

Frigo, L.C., Reas, D.L., \& LeCompte, D.C. (1999). Revelation without presentation: Counterfeit study list yields robust revelation effect. Memory \& Cognition, 27, 339-343.
Hicks, J.L., \& Marsh, R.L. (1998). A decrement-to-familiarity interpretation of the revelation effect from forced-choice tests of recognition memory. Journal of Experimental Psychology: Learning, Memory, and Cognition, 24, 11051120 .

LeCompte, D.L. (1995). Recollective experience in the revelation effect: Separating the contributions of revelation and familiarity. Memory \& Cognition, 23, 324-334.

Luo, C.R. (1993). Enhanced feelings of recognition: Effects of identifying and manipulating test items on recognition memory. Journal of Experimental Psychology: Learning, Memory, and Cognition, 19, 405-413.

Peynircioglu, Z.F., \& Tekcan, A.I. (1993). Revelation effect: Effort or priming does not create the sense of familiarity. Journal of Experimental Psychology: Learning, Memory, and Cognition, 19, 382-388.

Prull, M.W., Light, L.L., Collett, M.E., \& Kennison, R.F. (1998). Age-related differences in memory illusions: Revelation effect. Aging, Neuropsychology, and Cognition, 5, 147-165.

Tekcan, A.I., \& Peynircioglu, Z.F. (2001). Revelation effect: Effects of test conditions on face recognition. Turk Psikoloji Dergisi, 16, 57-70.

Watkins, M.J., \& Peynircioglu, Z.F. (1990). The revelation effect: When disguising test items induces recognition. Journal of Experimental Psychology: Learning, Memory, and Cognition, 16, 1012-1020.

Wells, G.L., Small, M., Penrod, S., Malpass, R.S., Fulero, S.M., \& Brimacombe, C.A.E. (1998). Eyewitness identification procedures: Recommendations for lineups and photospreads. Law and Human Behavior, 22, 603-647.

Westerman, D.L. (2000). Recollection-based recognition eliminates the revelation effect in memory. Memory \& Cognition, 28, 167-175.

Westerman, D.L., \& Greene, R.L. (1996). On the generality of the revelation effect. Journal of Experimental Psychology: Learning, Memory, and Cognition, 22, 1147-1153.

Westerman, D.L., \& Greene, R.L. (1998). The revelation that the revelation effect is not due to revelation. Journal of Experimental Psychology: Learning, Memory, and Cognition, 24, 377-386.

Yin, R.K. (1969). Looking at upside-down faces. Journal of Experimental Psychology, 81, 141-145. 